Check for updates

London, UK

limb@btinternet.com

Cite this as: BMJ 2020;370:m1789

http://dx.doi.org/10.1136/bmj.m1789

Published: 23 July 2020

\section{The BMJ Awards 2020: Research paper of the year}

\section{A study of antibiotics and maternal infections after childbirth had an "amazing" impact, reports Matthew Limb}

\section{Matthew Limb freelance journalist}

Using a single dose of prophylactic antibiotic after assisted vaginal birth would prevent thousands of infections and cut overall antibiotic use by $17 \%$, concluded the winning paper in the research paper of the year award in this year's BMJ Awards.

Senior author Marian Knight says a "fantastic team effort" by the UK's “unparalleled" obstetrics research network led to the findings, which are being "widely implemented into practice." She adds, "To have such an impact was amazing. As a researcher, you don't get many moments like that in your career."

Video 1 Award winners

The use of antibiotics during caesarean section is widely recommended. But routine antibiotic prophylaxis has not been recommended for operative vaginal birth (involving forceps or vacuum extraction), because of insufficient evidence of effectiveness.

The ANODE (prophylactic ANtibiotics for the prevention of infection following Operative DElivery) study was funded by the National Institute for Health Research. It was a blinded, randomised controlled trial involving 27 UK obstetric units between March 2016 and June 2018, and the results were published in the Lancet. $^{1}$

Some 1719 women received treatment-amoxicillin or clavulanic acid-intravenously, and 1708 were given a placebo (saline) about three hours after they had given birth.

Six weeks after giving birth, rates of perineal infection and perineal pain, use of pain relief for perineal pain, need for additional perineal care, and wound breakdown were significantly lower in the group of women who received a single dose of antibiotic.

Knight, from the National Perinatal Epidemiology Unit at the University of Oxford's Nuffield Department of Population Health, says that almost a fifth of women have an infection, and the results show this can be "reduced by almost half."

She adds, "This equates to prevention of over 7000 infections annually in the UK."

Overall, fewer antibiotics are needed. "We found that for each additional 100 doses of antibiotic used in prophylaxis, 168 treatment doses will be saved, representing a $17 \%$ overall reduction in antibiotic use," says Knight.
Knight M, Chiocchia V Partlett C, etalANODE collaborative group. Prophylactic antibiotics in the prevention of infection after operative vaginal delivery (ANODE): a multicentre randomised controlled trial. Lancet 2019;393:2395-403.

doi: 10.1016/S0140-6736(19)30773-1 pmid: 31097213 